\title{
Determination of densities and viscosities of canola oil biodiesel-diesel fuel-isopropyl alcohol blends
}

\author{
Mert Gülüm*, Atilla Bilgin \\ Department of Mechanical Engineering, Karadeniz Technical University, Trabzon, 61080, Turkey
}

\begin{abstract}
The aims of this study are to (1) investigate effects of isopropyl alcohol content in blend on changes of densities and kinematic viscosities of canola oil biodiesel-diesel fuel-isopropyl alcohol ternary blends, and (2) derive equations as a function of alcohol content in order to determine densities and to estimate kinematic viscosities of the ternary blends. For these aims, canola oil biodiesel was produced by means of transesterification, and blended with commercially available diesel fuel at the volume ratio of $20 \%$. Isopropyl alcohol was added to this biodiesel-diesel fuel blend at different volume ratios of 2, 4, 6, 8, 10, 15 and 20\%. Densities and kinematic viscosities of the prepared each fuels were measured at $15^{\circ} \mathrm{C}$ and $40^{\circ} \mathrm{C}$, respectively, according to ISO 4787 and DIN 53015 standards. Finally, regression equations were derived based on changes of density and viscosity versus alcohol content. According to results, linear equation for density-alcohol fraction variation and four-term exponential regression model for viscosity-alcohol fraction variation were derived.
\end{abstract}

Keywords: Canola oil biodiesel, transesterification, fuel properties, ternary blends, four-term exponential model

\section{Introduction}

In recent decades, the concerns over depletion of the world's petroleum reserves and environmental pollution have increased demand to develop a renewable and environmental friendly fuel [1]. Researchers think that an alternative fuel to diesel fuel must be technically possible, financially reasonable, friendly to environment, and readily available [2]. In this context, vegetable oils can be considered to be an alternative, but the main problem with the use of pure vegetable oils is related to its high viscosity, poor vaporization in the combustion chamber, difficulties of pumping and clogging of injectors over time [3][5]. These problems can be solved if the vegetable oils are chemically modified to biodiesel by means of transesterification [6]. Biodiesel, defined as the mono-alkyl esters of fatty acids derived from vegetable oils or animal fats, has many advantages such as higher cetane number, flash point temperature and lubricity characteristics, and lower carbon monoxide, unburned hydrocarbons, particulate matter and poly-aromatic hydrocarbons emissions, compared to diesel fuel [7]-[9]. Moreover, biodiesel is an environmentally friendly renewable fuel, and can help to reduce countries' dependence upon imported petroleum [7]. However, there are also some drawbacks of biodiesel like higher cost and viscosity, and poorer cold flow properties [6]. Blending of biodiesel with diesel fuel is one of the adopted techniques to overcome these difficulties [10].

The knowledge of temperature and blend percent dependence of viscosity or density of fuel is highly important in order to ensure optimal combustion [11]. Although researchers proposed a lot of models to predict kinematic viscosities of different biodiesel-diesel fuel blends as a function of temperature or blending ratio in literature [12]-[16], there are some studies about viscosity and density measurements of canola oil biodiesel (B100)/diesel fuel (DF)/isopropyl alcohol (iPA) ternary blends at different temperatures. Therefore, in this study, (1) canola oil biodiesel was produced by means of

\footnotetext{
*Manuscript received January 21, 2017; revised June 2, 2017.

Corresponding author. Tel.: +90 46237741 30; E-mail address: mertgulumm@ gmail.com

doi: $10.12720 /$ sgce.6.3.177-181
} 
transesterification, (2) the produced biodiesel was blended with DF at the volume ratio of $20 \%$, which is called as B20, (3) isopropyl alcohol was added to B20 at the volume ratios of 2 (iPA2), 4 (iPA4), 6 (iPA6), 8 (iPA8), 10 (iPA10), 15 (iPA15) and 20\% (iPA20), (4) densities and kinematic viscosities of all fuels (DF, B100, B20, iPA2, iPA4, iPA6, iPA8, iPA10, iPA15 and iPA20) were measured at $15^{\circ} \mathrm{C}$ and 40 ${ }^{\circ} \mathrm{C}$, respectively, and finally (5) linear equation to determine densities and four-term exponential model to estimate kinematic viscosities of the blends were derived.

\section{Materials and Methods}

\subsection{Materials}

To produce biodiesel by means of basic catalyzed transesterification, methanol, potassium hydroxide and anhydrous sodium sulphate (Merck, 99.6\% purity) were used.

\subsection{Biodiesel production}

Transesterification reaction parameters were taken as $1.00 \%$ catalyst concentration, $50^{\circ} \mathrm{C}$ reaction temperature, 60 minutes reaction time and 8:1 alcohol/oil molar ratio in [17]. Anhydrous sodium sulphate was used to remove moisture from washed biodiesel. More details of the biodiesel production were given in [8], [9], [18].

\subsection{Density measurement}

The densities of neat fuels (DF and B100) and blends (B20, iPA2, iPA4, iPA6, iPA8, iPA10, iPA15 and iPA20) were determined by means of pycnometer in accordance with ISO 4787 standard. Details of the measurements were given in [8], [9], [18].

\subsection{Dynamic viscosity measurement}

The dynamic viscosities were determined in accordance with DIN 53015 standard. Measurements were made by universal Haake Falling Ball Viscometer, Haake Water Bath and stopwatch. Details of the measurements were given in [8], [9], [18].

The kinematic viscosities were determined by dividing dynamic viscosity to density at the same temperature. If $\mu_{\text {biodiesel }}$ and $\rho_{\text {biodiesel }}$ are in the units of $(\mathrm{mPa} . \mathrm{s})$ and $(\mathrm{kg} / \mathrm{L})$, respectively, then $v_{\text {biodiesel }}$ is obtained in unit of $\left(\mathrm{mm}^{2} / \mathrm{s}\right)$. The measurements were conducted three times for each sample and the results were averaged.

\subsection{Uncertainty analysis}

In this study, uncertainties of the measured and calculated physical quantities such as dynamic and kinematic viscosities and densities were determined by the method proposed by [19]. According to this method, if the result $\mathrm{R}$ is a given function of the independent variables $\mathrm{x}_{1}, \mathrm{x}_{2}, \mathrm{x}_{3}, \ldots \mathrm{x}_{\mathrm{n}}$ and $\mathrm{w}_{1}, \mathrm{w}_{2}$, $\mathrm{w}_{3}, \ldots \mathrm{w}_{\mathrm{n}}$ are the uncertainties of each independent variables, then the uncertainty of the result $\mathrm{w}_{\mathrm{R}}$ is calculated by using the equation:

$$
\mathrm{w}_{\mathrm{R}}=\left[\left(\frac{\partial \mathrm{R}}{\partial \mathrm{x}_{1}} \cdot \mathrm{w}_{1}\right)^{2}+\left(\frac{\partial \mathrm{R}}{\partial \mathrm{x}_{2}} \cdot \mathrm{w}_{2}\right)^{2}+\cdots\left(\frac{\partial \mathrm{R}}{\partial \mathrm{x}_{\mathrm{n}}} \cdot \mathrm{w}_{\mathrm{n}}\right)^{2}\right]^{1 / 2}
$$

Determined highest uncertainty according to this method is $0.0871 \%$, which ensures that the results are fairly reliable.

\section{Result and Discussion}

Effect of isopropyl alcohol fraction on change of densities of the ternary blends is shown in Fig. 1, where points show the measured values at $15^{\circ} \mathrm{C}$ and solid line presents regression equation. The densities 
diminish with increasing in alcohol content in the blend due to lower density of isopropyl alcohol compared to that of diesel fuel and biodiesel. As well-known, because densities of blends are linearly proportional to alcohol percentage in the blend, a linear regression equation was fitted to the experimental data:

$$
\rho=\rho(X)=a+b X
$$

where $\rho$ is density in $\mathrm{kg} / \mathrm{m}^{3}, \mathrm{X}$ is volumetric alcohol fraction in the blend in $\%$, and a and $\mathrm{b}$ are regression constants.

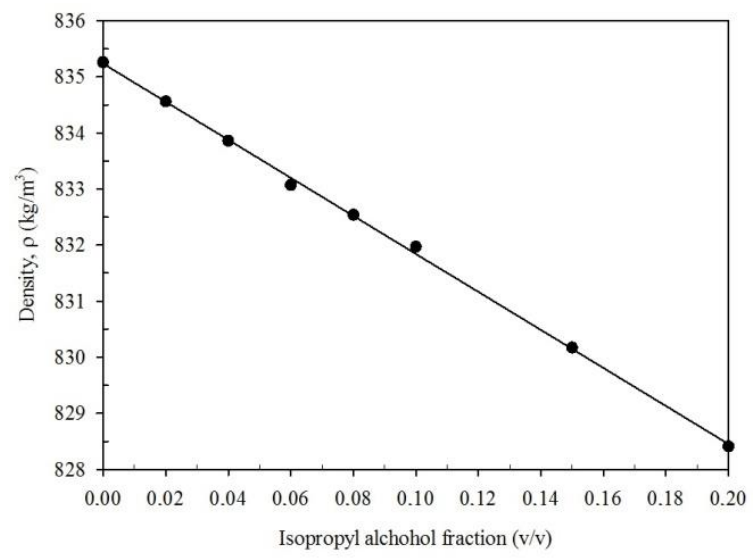

Fig. 1. Change of density vs. isopropyl alcohol fraction.

The measured density values at $15^{\circ} \mathrm{C}, \%$ relative errors between measured and calculated ones from Eq. 2 , regression constants and correlation coefficient $(\mathrm{R})$ are tabulated in Table 1 . The correlation coefficient and the \% maximum error were computed as 0.9999 and $0.0194 \%$, respectively. In fact, only two points, i.e. densities of B20 and isopropyl alcohol, are sufficient to derive linear equation to determine the densities of the blends. But, unlike alcohol, since biodiesel and diesel fuels are not pure substances, they have not fixed density points tabulated in the literature. For this reason more than two point measurements were carried out to improve the accuracy of the regression equation.

Table 1. Measured densities, errors of measured and calculated densities from Eq. (2) and regression parameters for different alcohol fractions

\begin{tabular}{cccccc}
\hline $\begin{array}{c}\text { Alcohol } \\
\text { fraction }\end{array}$ & $\begin{array}{c}\text { Measured } \\
\text { density }\end{array}$ & \multicolumn{2}{c}{$\begin{array}{c}\text { Regression } \\
\text { constants }\end{array}$} & $\mathrm{R}$ & $\begin{array}{c}\text { \% relative } \\
\text { errors }\end{array}$ \\
$(\%)$ & $\rho\left(\mathrm{kg} / \mathrm{m}^{3}\right)$ & $\mathrm{a}$ & $\mathrm{b}$ & & \\
\hline 0 & 835.26 & & & & 0.0072 \\
2 & 834.56 & & & 0.0046 \\
4 & 833.86 & & & 0.0020 \\
6 & 833.07 & $835.200-33.910$ & 0.9999 & 0.0115 \\
8 & 832.54 & & & 0.0063 \\
10 & 831.97 & & & 0.0194 \\
15 & 830.17 & & & 0.0068 \\
20 & 828.41 & & & 0.0010 \\
\hline
\end{tabular}

Fig. 2 illustrates kinematic viscosity change with respect to isopropyl alcohol fraction. As shown in this figure, viscosity non-linearly decreases with increasing in alcohol content. The distribution of viscosity with respect to alcohol content was correlated by the following four-term exponential model:

$$
v=v(X)=a e^{-b X}+c e^{-d X}
$$

where $v$ is kinematic viscosity in $\mathrm{mm}^{2} / \mathrm{s}$, and a, b, c and $\mathrm{d}$ are regression constants. 


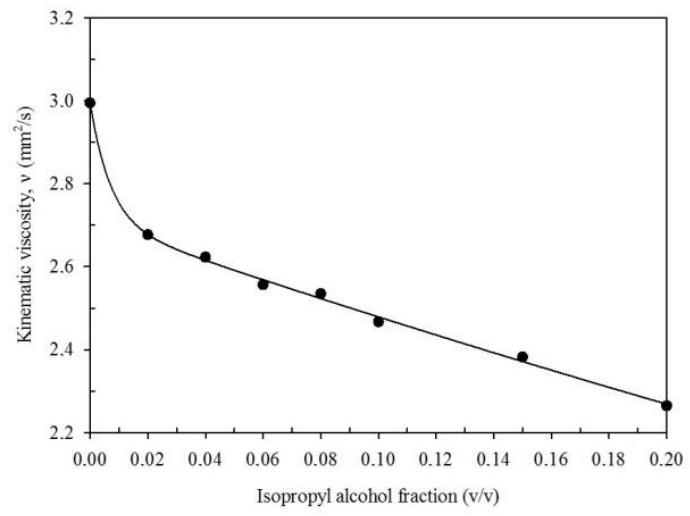

Fig. 2. Change of viscosity vs. isopropyl alcohol fraction.

Table 2 lists measured viscosities at $40^{\circ} \mathrm{C}$, regression constants, correlation coefficient and errors. For four-term exponential model, the maximum relative error for iPA6 blend and correlation coefficient were computed as $0.4969 \%$ and 0.9991 . According to these results, the four-term exponential model has adequate high accuracy in calculating viscosities of each blend.

Table 2. Measured viscosities, errors of measured and calculated viscosities from Eq. (3) and regression parameters for different alcohol fractions

\begin{tabular}{|c|c|c|c|c|c|c|c|}
\hline \multirow{2}{*}{$\begin{array}{c}\text { Alcohol } \\
\text { fraction } \\
\mathrm{X}(\%) \\
\end{array}$} & \multirow{2}{*}{$\begin{array}{l}\text { Measured } \\
\text { viscosity } \\
v\left(\mathrm{~mm}^{2} / \mathrm{s}\right)\end{array}$} & \multicolumn{4}{|c|}{ Regression constants } & \multirow{2}{*}{$\mathrm{R}$} & \multirow{2}{*}{$\begin{array}{c}\% \text { relative } \\
\text { errors }\end{array}$} \\
\hline & & $\mathrm{a}$ & $\mathrm{b}$ & $\mathrm{c}$ & $\mathrm{d}$ & & \\
\hline 0 & 2.995 & \multirow{8}{*}{0.2862} & \multirow{8}{*}{141.6} & \multirow{8}{*}{2.7090} & \multirow{8}{*}{0.8867} & \multirow{8}{*}{0.9991} & 0.0067 \\
\hline 2 & 2.677 & & & & & & 0.0462 \\
\hline 4 & 2.622 & & & & & & 0.2443 \\
\hline 6 & 2.556 & & & & & & 0.4969 \\
\hline 8 & 2.535 & & & & & & 0.4538 \\
\hline 10 & 2.467 & & & & & & 0.4919 \\
\hline 15 & 2.382 & & & & & & 0.4356 \\
\hline 20 & 2.264 & & & & & & 0.2109 \\
\hline
\end{tabular}

\section{Conclusion}

In this study, effects of isopropyl alcohol fraction in blend on the densities and kinematic viscosities of canola oil biodiesel-commercially available diesel fuel-isopropyl alcohol ternary blends were determined. Moreover, regression equations as a function of alcohol content were derived to estimate viscosities and to determine densities of the ternary blends. The following conclusions can be drawn from this study:

- Correlation coefficient (R) and the maximum relative error for linear density-alcohol fraction variation equation were computed as 0.9999 and $0.0194 \%$ respectively.

- Four-term exponential model with correlation coefficient of 0.9991 shows quite high degree of accuracy for representing change of kinematic viscosity with respect to alcohol content. Maximum relative error between the measured and calculated viscosity values were determined as $0.4969 \%$.

- There is two different characteristic regions in the change of kinematic viscosity with respect to alcohol content. In the first part including range from 0 and $0.04 \%$ of alcohol fraction, variation of viscosity vs. alcohol content shows typical exponential characteristic, while in the second part including range from $0.04 \%$ and $0.20 \%$ of alcohol fraction, variation of viscosity vs. alcohol content tends to linear characteristic.

In the light of this work, researchers could try to develop new or general models to estimate other fuel properties such as heating value, cetane number, acid value etc. of different biodiesel-diesel binary or biodiesel-diesel-alcohol ternary blends for future studies. 


\section{Acknowledgement}

The authors express their gratitude to Karadeniz Technical University Scientific Research Projects Fund for financial support received (Project No: 9745).

\section{References}

[1] Sajjadi B, Raman AAA, Arandiyan H. A comprehensive review on properties of edible and non-edible vegetable oil-based biodiesel: composition, specifications and prediction models. Renewable and Sustainable Energy Reviews, 2016; 63:62-92.

[2] Verma P, Sharma MP. Review of process parameters for biodiesel production from different feedstocks. Renewable and Sustainable Energy Reviews, 2016; 62:1063-1071.

[3] Nielsen PM, Brask J, Fjerbaek L. Enzymatic biodiesel production: technical and economical considerations. Eur. J. Lipid Sci. Technol., 2008; 110:692-700.

[4] Pabyam MS, N'Tsoukpoe E, Blin J, Azoumah Y. Transesterification of various bio-oils: application and perspectives in Burkina Faso. Petroleum\&Environmental Biotechnology, 2015;6(1):1-6.

[5] Demirbas A. Biodiesel production via non-catalytic SCF method and biodiesel fuel characteristics. Energy Conversion and Management, 2006; 47(15-16):2271-2282.

[6] Baroutian S, Aroua MK, Raman AAA, Sulaiman NMN. Viscosities and densities of binary and ternary blends of palm oil+palm biodiesel+diesel fuel at different temperatures. J. Chem. Eng. Data, 2010; 55(1):504-507.

[7] Dunn RO, Knothe G. Alternative diesel fuels from vegetable oils and animal fats. J. Oleo Sci., 2001;50(5):415-426.

[8] Gülüm M, Bilgin A, Density, flash point and heating value variations of corn oil biodiesel-diesel fuel blends. Fuel Processing Technology, 2015; 134:456-464.

[9] Gülüm M, Bilgin A. Two-term power models for estimating kinematic viscosities of different biodiesel-diesel fuel blends. Fuel Processing Technology, 2016;149:121-130.

[10] Gaonkar N, Vaidya RG. Engineering of viscosity of biodiesel blends: a novel approach. Energy Efficient Technologies for Sustainability, 2016;1:1-4.

[11] Gaonkar N, Vaidya RG. A simple model to predict the biodiesel blend density as simultaneous function of blend percent and temperature. Environmental Science and Pollution Research, 2016;23:9260-9264.

[12] Abolle A, Kouakou L, Planche H. The viscosity of diesel oil and mixtures with straight vegetable oils: palm, cabbage palm, cotton, groundnut, copra and sunflower. Biomass and Bioenergy, 2009;33:1116-1121.

[13] Kumbar V, Dostal P. Temperature dependence density and kinematic viscosity of petrol, bioethanol and their blends. Pak. $J$. Agri. Sci., 2014;51:175-179.

[14] Al-Hamamre Z, Al-Salaymeh A. Physical properties of (jojoba oil+biodiesel), (jojoba oil+diesel) and (biodiesel+diesel) blends. Fuel, 2014;123:175-188.

[15] Shuman G, Zhenzhong Y, Yuguo G. Effect of adding biodiesel to diesel on the physical and chemical properties and engine performance of fuel blends. Journal of Biobased Materials and Bioenergy, 2016;10:34-43.

[16] Rawajfeh K, Al-Hamamre Z. Study on the viscosity of jojoba oil blends with biodiesel or petroleum diesel. Energy Sources, Part A: Recovery, Utilization, and Environmental Effects, 2016;38:3290-3299.

[17] Karabas H. Investigation of biodiesel fuel from canola oil using various reaction parameters. International Journal of Automotive Engineering and Technologies, 2013;2:85-91.

[18] Gülüm M, Bilgin A, Cakmak A. Comparison of optimum reaction parameters of corn oil biodiesels produced by using sodium hydroxide $(\mathrm{NaOH})$ and potassium hydroxide $(\mathrm{KOH})$. Journal of the Faculty of Engineering and Architecture of Gazi University, 2015;30:503-511.

[19] Holman JP. Experimental Methods for Engineers. $8^{\text {th }}$ ed., New York: McGraw-Hill; 2012. 